\title{
COVID-19, acute respiratory distress syndrome (ARDS), and hyperbaric oxygen therapy (HBOT): what is the link?
}

\author{
Antonio De Maio ${ }^{1,2,3} \cdot$ Lawrence E. Hightower ${ }^{4}$
}

Published online: 18 May 2020

(C) Cell Stress Society International 2020

The current coronavirus disease 2019 (COVID-19) pandemic has become an unprecedented challenge for the healthcare system worldwide, with an overwhelming number of patients requiring clinical attention and an unacceptably high mortality rate within critical care facilities. COVID-19 is caused by a novel enveloped virus containing a single positive RNA strand, designated severe acute respiratory syndrome coronavirus 2 (SARS-CoV-2), first identified in China. The virus shows a high rate of infection, spreading very rapidly among the population that, in this era of swift international connections, has resulted in a global pandemic. The lack of drug treatments and vaccines for this condition has resulted in a mitigation approach to avoid community transmission, consisting of a general lockdown of the populations producing a tremendous burden for the global economy.

The first SARS virus, SARS-CoV, also appeared in China and spread to at least 29 countries during 2002-2003. The most frequent cause of death from this virus was respiratory insufficiency with subsequent respiratory failure. What little we know about SARS-CoV-2 is based mainly on SARS-CoV and a small number of other animal coronaviruses. These viruses cause damage to tissues and organs of the infected host by direct infection of target cells or indirectly by prolonged activation of host defense responses. The virus has been

Lawrence E. Hightower

lawrence.hightower@uconn.edu

1 Division of Trauma, Critical Care, Burns, and Acute Care Surgery, Department of Surgery, University of California San Diego, La Jolla, San Diego, CA 92093, USA

2 Department of Neurosciences, University of California San Diego, La Jolla, San Diego, CA 92093, USA

3 Center for Investigations of Health and Education Disparities, School of Medicine, University of California San Diego, La Jolla, San Diego, CA 92093, USA

4 Department of Molecular and Cell Biology, University of Connecticut, Storrs, Mansfield, CT 06269, USA detected in the lungs and immune cells of patients who have succumbed to the infection, consistent with direct injury to the pulmonary tissue and activation of the immune response. Activation of the innate immune system stimulates the production of chemokines and cytokines as part of the inflammatory defense response. As a result, neutrophils and macrophages, among other immune system cells, are drawn to infected tissues. Macrophage activation is accompanied by the release of more chemokines creating a two-edged sword capable of both killing virus-infected cells and damaging normal host tissues (reviewed in Perlman and Dandekar 2005). If these activated leukocytes remained at the site of lung infection, the lethality of SARS-CoV-2 virus likely would be lower, but unfortunately, both the chemokine/cytokine "storm" and infected/activated leukocytes released into the circulation by damaged lung tissue affect several organs, of which the brain, kidneys, and heart are particularly susceptible (Huang et al. 2005). Leukocyte extravasation has drug targets that should be explored for COVID-19 patients. As we will discuss in more detail, proteins of the infecting coronavirus interfere with these host responses, possibly causing imbalances that result in immunopathogenesis.

The uncertainty about the biology and pathology of a new virus has limited our ability to make predictions about possible treatments and has interfered with the ability of epidemiologists to formulate credible models for the pandemic spread. In contrast, the rapid sequencing of the viral genome has been key in the prompt development of a diagnostic test to detect the presence of the virus. In spite of this information, the prospect of producing an efficient vaccine is still months if not years away. Therefore, immediate solutions are necessary to reduce the burden of this disease. In this regard, an understanding of the basic pathophysiology underlying COVID-19 is critical. Emergency room and critical care doctors and nurses along with hospital staff and EMTs have done heroic work caring for patients and providing essential information on the nature of this chameleon-like illness. Dr. Richard Levitan, an emergency physician at Bellevue Hospital in 
New York City, made some striking patient observations regarding blood $\mathrm{O}_{2}$ levels that he shared in a New York Times opinion piece (20 April 2020). He noted that the initial stage of COVID-19 pneumonia is only now being understood as "silent hypoxia," alluding to its "insidious, hard-to-detect nature" as he described it. Oxygen saturation levels fell from the normal range $94-100 \%$ to as low as $50 \%$, but patients did not experience shortness of breath until the depleted levels reached critical values because $\mathrm{CO}_{2}$ continued to be released. By the time $\mathrm{CO}_{2}$ does start to accumulate, triggering a feeling of breathlessness, many COVID-19 patients progress quickly into respiratory failure.

Although the initial insult is the infection by SARS-CoV-2, morbidity and mortality from this condition are due to the incidence of acute respiratory distress syndrome (ARDS), which is defined as a condition of extremely low arterial oxygen concentration or hypoxia with a ratio of partial pressure arterial oxygen and fraction of inspired oxygen $(\mathrm{PaO} 2 / \mathrm{FiO} 2$ ratio) less than 300 and bilateral pulmonary thickness (ARDS Definition Task Force et al. 2012). The development of ARDS is likely the product of inflammation mounted by the patient's own response to the infection. When a localized infection is produced, the body activates the innate immune response in which immune cells, particularly neutrophils and monocytes, infiltrate the tissue to combat the foreign particles. These cells release a battery of toxic agents to kill the pathogen. However, these antipathogenic agents also harm the surrounding tissue, creating a focus of necrosis that results in the release of cellular debris that activates a secondary inflammatory response. The evolutionary compromise has been that some tissue damage is acceptable if the source of infection is eradicated. However, if the inflammatory process is not contained or controlled, it could spread systemically affecting other organs, the function of which may be compromised, resulting in metabolic distress and subsequent organ collapse, known as multiple organ failure (MOF) or multiple organ dysfunction syndrome (MODS) (Fry et al. 1980; Marshall et al. 1995). Thus, the clinical observations that secondary organs are affected during COVID-19 may not be a direct effect of the viral attack to these tissues, but organ deterioration due to an uncontrolled inflammatory response that ends in shock, MOF, and death.

From the perspective of the cell stress and chaperone field, we are interested in the abilities of SARS-CoV-2 to modulate inducible cellular stress responses, including the innate immune pathways and the inflammatory response pathways. These abilities are likely to be important for the COVID-19 links to ARDS. Weiss and coworkers have reported that MERS-CoV, another coronavirus that causes severe respiratory disease in humans, produces at least two accessory proteins NS4a and NS4b that dramatically suppress the activation of antiviral innate immune pathways (Comar et al. 2019). Research into the classical heat shock response has revealed a composite of pathways, including the unfolded protein response (UPR), the proteotoxic stress response (PSR), and the metabolic stress response (MSR). SARS-CoV is known to modulate the UPR, possibly due to the accumulation of the spike glycoprotein in the endoplasmic reticulum of infected human cultured cells (Chan et al. 2006). Proteins originally named GRP78 and GRP94, now as HSPA5 and HSPC4, respectively, are induced as part of the UPR, capable of triggering apoptosis. The mRNAs encoding these stress response proteins escape the translational block on most cellular protein synthesis imposed by infected cells, so they are available to trigger additional damage by apoptosis or necrosis at the site of coronaviral infection. In one of the few papers that report about properties of SARS-CoV-2 proteins, Gordon and coworkers (Gordon et al. 2020) identified the human proteins from cells transfected with genes encoding SARS-CoV-2 polypeptides physically associated with 26 of the 29 viral proteins expressed in cells using affinity purification-mass spectrometry. They found 332 highconfidence protein-protein interactions. Of particular interest here is that Nsp7 and Nsp4 bound to DNAJC19 and DNAJC11, respectively, co-chaperones located within mitochondria. DNAJC19 is associated with cardiomyopathy (Richter-Dennerlein et al. 2014), and DNAJC11 has been linked to a neuromuscular pathology in mice (Ioakeimidis et al. 2014). Two additional viral proteins, $M$ and Nsp5, have links to mitochondrial matrix function.

The incidence of ARDS and MOD/MODS is not unique to respiratory viral infections. It can be triggered by a variety of insults, including other infections (e.g., bacterial, fungal) or even in the absence of a pathogenic agent during trauma or injury (Vincent 2017). Indeed, ARDS is a common feature in the development of sepsis and septic shock that has been defined as a lifethreatening organ dysfunction condition caused by a dysregulated host response to infection (Singer et al. 2016; Coopersmith and Deutschman 2017), resulting in the inability to restore homeostasis (Deutschman and Tracey 2014). Therefore, it may be possible to learn something about the etiology of COVID-19 based on our current understanding of the response to sepsis and injury. For example, the great variability of patients' responses to the SARS-CoV-2 infection, from asymptomatic individuals to mild and severe cases, could be explained by the multifactorial response to injury. Thus, the disparate outcomes of infection have been postulated to be the combination of multiple factors, including the nature and extent of infection or injury, the genetic background of the subject, sex, and age. Non-genetic factors also play a role, such as the environment and the physical condition of the patient. These factors can be modulated further by underlying conditions such as obesity, alcohol drinking, smoking, and any other preexisting conditions, like diabetes, cardiovascular disease, and high blood pressure (De Maio et al. 2005).

The absence of drug treatments to limit lethality and vaccines to curve down COVID-19 infections have left clinicians with the single option of using supportive therapy as the only intervention, such as the delivery of oxygen and fluids, and 
mechanical ventilation as the last resource. Experimental animal studies about the response to sepsis have suggested that early interventions are critical to ameliorate the condition, such as source control of the infection or injury (Cauvi et al. 2012; Cauvi et al. 2019), the use of antibiotics (Puskarich et al. 2009), or a reduction in the inflammatory response (Halbach et al. 2019). Indeed, the Surviving Sepsis Campaign calls for early administration of supportive therapy (e.g., antibiotics and fluids) to ameliorate the disease (http://www. survivingsepsis.org). If we extrapolate these observations to the COVID-19 situation, an early intervention before the need for mechanical ventilation could be of extraordinary utility for saving lives. In this regard, hyperbaric oxygen therapy (HBOT) that consists of exposure to $100 \%$ oxygen under increased atmospheric pressure up to $2.4 \mathrm{~atm}$ could be a great resource to improve the outcome from the infection when it is administered at early stages as soon as a reduction of arterial oxygen concentration is detected. Indeed, experimental animal studies have shown that an initial HBOT improved dramatically the outcome from sepsis, which was correlated with a reduction of the inflammatory response triggered by the initial insult (Halbach et al. 2019). The great advantage of HBOT is that it delivers oxygen at elevated partial pressure allowing this gas to penetrate tissues very rapidly and in higher concentration, which is more effective than hemoglobin oxygen delivery. Both mechanical ventilators, the current treatment for severely ill hypoxic COVID-19 patients in critical care, and HBOT are able to elevate the levels of arterial $\mathrm{O}_{2}$, but in addition, HBOT provides a crucial function that ventilators lack. The increased concentration of $\mathrm{O}_{2}$ delivered to cells in tissues by HBOT at $2.4 \mathrm{~atm}$ provides a signal for cells to induce two powerful transcription factors, Nrf- 2 which stimulates the production of literally hundreds of cell defense proteins most of which participate in oxidative stress responses and heat shock transcription factor 1 which induces cells to produce additional defense proteins that are also antiinflammatory (Godman et al. 2010). The elevated supply of oxygen is likely to preserve cellular metabolism and organ function. Indeed, HBOT has been reported to improve mitochondrial function (Tezgin et al. 2020). Moreover, HBOT alters the balance between glycolysis and mitochondrial respiration, possibly countering an effect of viral infection on cellular caloristasis networks (Tezgin et al. 2020) and improving hypoxia in COVID-19 patients. An additional advantage of HBOT is its capacity to reduce the inflammatory response (Buras et al. 2006; Halbach et al. 2019). Several studies have shown that HBOT improves kidney function after infection (Edremitlioglu et al. 2005) and reduces kidney damage in diabetic patients (Harrison et al. 2018). It has also been reported to protect from ischemia/reperfusion injury (Buras and Reenstra 2007; Yu et al. 2005) and diminish UV skin damage (Fuller et al. 2013).
HBOT has been used extensively with great safety in the treatment of patients for a variety of maladies. HBOT is the treatment of choice for carbon monoxide poisoning and gas embolism (Goodman 1964; Tibbles and Edelsberg 1996). It has been very effective in the treatment of diabetic ulcers (Gill and Bell 2004; Stoekenbroek et al. 2014) and radiation injury (Kirby 2019a) and in the improvement of wound healing (Kirby 2019b). Therefore, HBOT could be a potential intervention to improve the outcome of COVID-19 patients. It has been shown to be safe during the use of mechanical ventilation (Bessereau et al. 2017). A small study from China has shown excellent potential for its use in the treatment of COVID-19 patients (https://drive.google.com/file/d/ 1pjtuT44daBvc8LubVYcR064PLpgIjiFY/view). In this study, five critically ill patients with COVID-19 and signs of hypoxia were subjected to HBOT. After two treatments, a dramatic improvement in the clinical condition of the patients was observed with an increase in blood oxygen saturation level and reduced lung inflammation, as observed by CT scans. There were no concerns about viral contamination and the spread of the disease to medical attendants.

All of these observations pointed out that HBOT could be a useful tool for improving the conditions of COVID-19 patients, particularly if the intervention occurs at early stages, although it could also be positive during the intubation period. Obviously, there are some logistics in the use of HBOT in the ICU setting. Hyperbaric chambers occupy significant space, and they may not be available continuously to the ICU units. Thus, patients need to be transported to the HBOT facility. In addition, the number of bed settings per chamber is limited. It would be of great utility to have portable chambers that could be easily installed within the patient ICU bed. Although we appear highly enthusiastic about the potential role of HBOT in the treatment of COVID-19 patients, sound clinical trials are needed to test whether or not this intervention could save lives during the current pandemic.

\section{References}

ARDS Definition Task Force, Ranieri VM, Rubenfeld GD, Thompson BT, Ferguson ND, Caldwell E, Fan E et al (2012) Acute respiratory distress syndrome: the Berlin Definition. JAMA 307:2526-2533. https://doi.org/10.1001/jama.2012.5669

Bessereau J, Aboab J, Hullin T, Huon-Bessereau A, Bourgeois JL, Brun PM, Chevret S, Annane D (2017) Safety of hyperbaric oxygen therapy in mechanically ventilated patients. Int Marit Health 68:46-51. https://doi.org/10.5603/IMH.2017.0008

Buras JA, Reenstra WR (2007) Endothelial-neutrophil interactions during ischemia and reperfusion injury: basic mechanisms of hyperbaric oxygen. Neurol Res 29:127-131. https://doi.org/10.1179/ $016164107 X 174147$

Buras JA, Holt D, Orlow D, Belikoff B, Pavlides S, Reenstra WR (2006) Hyperbaric oxygen protects from sepsis mortality via an interleukin- 
10-dependent mechanism. Crit Care Med 34:2624-2629. https:// doi.org/10.1097/01.CCM.0000239438.22758.E0

Cauvi DM, Song D, Vazquez DE, Hawisher D, Bermudez JA, Williams MR, Bickler S, Coimbra R, de Maio A (2012) Period of irreversible therapeutic intervention during sepsis correlates with phase of innate immune dysfunction. J Biol Chem 287:19804-19815. https://doi. org/10.1074/jbc.M112.359562

Cauvi DM, Hawisher D, Dores-Silva PR, Lizardo RE, De Maio A (2019) Macrophage reprogramming by negatively charged membrane phospholipids controls infection. FASEB J 33:2995-3009. https:// doi.org/10.1096/fj.201801579R

Chan C-P, Siu K-L, Chin K-T, Yuen K-Y, Zheng B, Jin D-Y (2006) Modulation of the unfolded protein response by the severe acute respiratory syndrome coronavirus spike protein. J Virol 80:92799287. https://doi.org/10.1128/JVI.00659-06

Comar CE, Goldstein SA, Li Y, Yount B, Baric RS, Weiss SR (2019) Antagonism of dsRNA-induced innate immune pathways by NS4a and NS4b accessory proteins during MERS coronavirus infection. mBio 10:e00319-e00319. https://doi.org/10.1128/mBio.00319-19

Coopersmith CM, Deutschman CS (2017) The new Sepsis definitions: implications for the basic and translational research communities. Shock 47:264-268. https://doi.org/10.1097/SHK. 0000000000000763

De Maio A, Torres MB, Reeves RH (2005) Genetic determinants influencing the response to injury, inflammation, and sepsis. Shock 23:11-17. https://doi.org/10.1097/01.shk.0000144134. 03598.c5

Deutschman CS, Tracey KJ (2014) Sepsis: current dogma and new perspectives. Immunity 40:463-475. https://doi.org/10.1016/j.immuni. 2014.04.001

Edremitlioglu M, Kilic D, Oter S, Kisa U, Korkmaz A, Coskun O, Bedir $\mathrm{O}$ (2005) The effect of hyperbaric oxygen treatment on the renal functions in septic rats: relation to oxidative damage. Surg Today 35:653-661. https://doi.org/10.1007/s00595-004-3000-5

Fry DE, Pearlstein L, Fulton RL, Polk HC Jr (1980) Multiple system organ failure. The role of uncontrolled infection. Arch Surg 115: 136-140. https://doi.org/10.1001/archsurg.1980.01380020006003

Fuller AM, Giardina C, Hightower LE, Perdrizet GA, Tierney CA (2013) Hyperbaric oxygen preconditioning protects skin from UV-A damage. Cell Stress Chaperones 18:97-107. https://doi.org/10.1007/ s12192-012-036-2

Gill AL, Bell CN (2004) Hyperbaric oxygen: its uses, mechanisms of action and outcomes. QJM 97:385-395. https://doi.org/10.1093/ qjimed/hch074

Godman CA, Chheda KP, Hightower LE, Perdrizet G, Shin D-G, Giardina C (2010) Hyperbaric oxygen induces a cytoprotective and angiogenic response in human microvascular endothelial cells. Cell Stress Chaperones 15:431-442. https://doi.org/10.1007/ s12192-009-0159-0

Goodman MW (1964) Decompression sickness treated with compression to 2-6 atmospheres absolute; report of fourteen cases, discussions and suggestions for a minimal pressure-oxygen breathing therapeutic profile. Aerosp Med 35:1204-1212

Gordon DE, et al (2020) A SARS-CoV-2-human protein-protein interaction map reveals drug targets and potential drug-repurposing. bioRxiv:2020.2003.2022.002386. https://doi.org/10.1101/2020.03. 22.002386

Halbach JL, Prieto JM, Wang AW, Hawisher D, Cauvi DM, Reyes T, Okerblom J, Ramirez-Sanchez I, Villarreal F, Patel HH, Bickler SW, Perdrizet GA, de Maio A (2019) Early hyperbaric oxygen therapy improves survival in a model of severe sepsis. Am J Physiol Regul Integr Comp Physiol 317:R160-R168. https://doi. org/10.1152/ajpregu.00083.2019

Harrison LE, Giardina C, Hightower LE, Anderson C, Perdrizet GA (2018) Might hyperbaric oxygen therapy (HBOT) reduce renal injury in diabetic people with diabetes mellitus? From preclinical models to human metabolomics. Cell Stress Chaperones 23:11431152. https://doi.org/10.1007/s12192-018-0944-8

Huang K-J, Su I-J, Theron M, Wu Y-C, Lai S-K, Liu C-C, Lei H-Y (2005) An interferon- $\gamma$-related cytokine storm in SARS patients. J Med Virol 75:185-194. https://doi.org/10.1002/jmv.20255

Ioakeimidis F, Ott C, Kozjak-Pavlovic V, Violitzi F, Rinotas V, Makrinou E, Eliopoulos E, Fasseas C, Kollias G, Douni E (2014) A splicing mutation in the novel mitochondrial protein DNAJC11 causes motor neuron pathology associated with cristae disorganization, and lymphoid abnormalities in mice. PLoS One 9:e104237e104237. https://doi.org/10.1371/journal.pone.0104237

Kirby JP (2019a) Hyperbaric oxygen therapy and radiation-induced injuries. Mo Med 116:198-200

Kirby JP (2019b) Hyperbaric oxygen therapy and negative pressure as advanced wound management. Mo Med 116:192-197

Marshall JC, Cook DJ, Christou NV, Bernard GR, Sprung CL, Sibbald WJ (1995) Multiple organ dysfunction score: a reliable descriptor of a complex clinical outcome. Crit Care Med 23:1638-1652. https:// doi.org/10.1097/00003246-199510000-00007

Perlman S, Dandekar AA (2005) Immunopathogenesis of coronavirus infections: implications for SARS. Nat Rev Immunol 5:917-927. https://doi.org/10.1038/nri1732

Puskarich MA, Runyon MS, Trzeciak S, Kline JA, Jones AE (2009) One year mortality of patients treated with an emergency department based early goal directed therapy protocol for severe sepsis and septic shock: a before and after study. Crit Care 13:R167. https:// doi.org/10.1186/cc8138

Richter-Dennerlein R, Korwitz A, Haag M, Tatsuta T, Dargazanli S, Baker M, Decker T, Lamkemeyer T, Rugarli EI, Langer T (2014) DNAJC19, a mitochondrial cochaperone associated with cardiomyopathy, forms a complex with prohibitins to regulate cardiolipin remodeling. Cell Metab 20:158-171. https://doi.org/10.1016/j. cmet.2014.04.016

Singer M, Deutschman CS, Seymour CW, Shankar-Hari M, Annane D, Bauer M, Bellomo R, Bernard GR, Chiche JD, Coopersmith CM, Hotchkiss RS, Levy MM, Marshall JC, Martin GS, Opal SM, Rubenfeld GD, van der Poll T, Vincent JL, Angus DC (2016) The third international consensus definitions for sepsis and septic shock (sepsis-3). JAMA 315:801-810. https://doi.org/10.1001/jama.2016.0287

Stoekenbroek RM, Santema TB, Legemate DA, Ubbink DT, van den Brink A, Koelemay MJ (2014) Hyperbaric oxygen for the treatment of diabetic foot ulcers: a systematic review. Eur J Vasc Endovasc Surg 47:647-655. https://doi.org/10.1016/j.ejvs.2014.03.005

Tezgin D, Giardina C, Perdrizet GA, Hightower LE (2020 Apr 6) The effect of hyperbaric oxygen on mitochondrial and glycolytic energy metabolism: the caloristasis concept. Cell Stress Chaperones. https:// doi.org/10.1007/s12192-020-01100-5

Tibbles PM, Edelsberg JS (1996) Hyperbaric-oxygen therapy. N Engl J Med 334:1642-1648. https://doi.org/10.1056/ NEJM199606203342506

Vincent JL (2017) High-frequency oscillation in acute respiratory distress syndrome. The end of the story? Am J Respir Crit Care Med 196: 670-671. https://doi.org/10.1164/rccm.201703-0475ED

Yu SY, Chiu JH, Yang SD, Yu HY, Hsieh CC, Chen PJ, Lui WY, Wu CW (2005) Preconditioned hyperbaric oxygenation protects the liver against ischemia-reperfusion injury in rats. J Surg Res 128:28-36. https://doi.org/10.1016/j.jss.2005.04.025

Publisher's note Springer Nature remains neutral with regard to jurisdictional claims in published maps and institutional affiliations. 